九州大学学術情報リポジトリ

Kyushu University Institutional Repository

Evaluation of the Edge-effect on the Farmland Production Environment in Hilly and MOuntainous Areas (1): Spatial and Temporal Changes of Solar Radiation Environment

Yuge, Kozue

Faculty of Agriculture, Kyushu University

Haraguchi, Tomokazu

Faculty of Agriculture, Saga University

Anan, Mitsumasa

Graduate School of Bioresource and Bioenvironmental Sciences, Kyushu University

Nakano, Yoshisuke

Faculty of Agriculture, Kyushu University

https://doi.org/10.5109/9302

出版情報：九州大学大学院農学研究院紀要. 52 (1)，pp. 175-178，2007-02-28. Faculty of Agriculture, Kyushu University

バージョン：

権利関係 : 


\title{
Evaluation of the Edge-effect on the Farmland Production Environment in Hilly and Mountainous Areas (1)-Spatial and Temporal Changes of Solar Radiation Environment-
}

\author{
Kozue YUGE*, Tomokazu HARAGUCHI' ${ }^{1}$, Mitsumasa ANAN ${ }^{2}$ \\ and Yoshisuke NAKANO \\ Laboratory of Irrigation and Water Utilization, Division of Regional Environment Science, \\ Department of Bioproduction Environmental Sciences, Faculty of Agriculture, \\ Kyushu University, Fukuoka 812-8581, Japan \\ (Received November 10, 2006 and accepted December 1, 2006)
}

\begin{abstract}
The objective of this study is quantification of the solar radiation in the farmland located in the hilly and mountainous areas, considering the effect of the shelter adjacent to the field, such as the forest (This effect is called as the edge-effect in this study.). To evaluate the edge-effect on the solar radiation environment in the farmland, solar radiations are measured at the center and edge of the study site adjacent to the forest. The simulation model is composed, coupling with the fish-eye projection method and procedure for the separating direct and diffuse solar radiations. Using this model, the diurnal solar radiations are simulated at the center and edge of the study site. The simulation result showed good agreement with the observation. The spatial distribution of the solar radiation in an observational field is quantified by this method, considering the edge-effect. The simulation result indicated that the solar radiation environment on the field surface is affected by the shelter adjacent to the field and the field direction.
\end{abstract}

\section{INTRODUCTION}

In Japan, most of the farmland is located in the hilly and mountainous areas, and the maintaining the agricultural productivity of the farmland in the hilly and mountainous areas is very important from the viewpoint of the conservancy of the rural area. One of the most important micrometeorological factors for agricultural production is solar radiation. It affects the crop growth condition, water consumption, and thermal environment at the farmland. The solar radiation environment on the surface of the farmland located in the hilly and mountainous areas is very complicated because it is affected by the shelter adjacent to the field, such as the forest, and the topographic feature.

The solar radiation environment in the hilly and mountainous areas has been studied. Miura et al. (1980) established the calculation method of the solar radiation distribution in the mountainous area. Nakano et al. (2005) studied the solar radiation distribution change affected by the land consolidation in the hilly and mountainous areas. These studies are effective for quantifying the solar insolation in the hilly and mountainous areas, considering the topographic feature of the farmland. However the method to evaluate the solar radiation environment, considering the shelter effect (This effect is called as the edge-effect in this study.), has not yet been established.

${ }^{1}$ Laboratory of Agricultural Water Supply and Management, Department of Agricultural Sciences, Faculty of Agriculture, Saga University, Saga

${ }^{2}$ Laboratory of Irrigation and Water Utilization, Division of Regional Environment Science, Department of Bioproduction Environmental Sciences, Graduate School of Bioresource and Bioenvironmental Sciences, Kyushu University

* Corresponding author (E-mail: yuge@bpes.kyushu-u.ac.jp)
The objective of this study is quantification of the solar radiation at the farmland located in the hilly and mountainous areas, considering the edge-effect. To evaluate the edge-effect on the solar radiation environment in the field, the fish-eye projection method is introduced in this study. This method for estimating light interception by a canopy was studied by Anderson (1964) and Kurata et al. (1988). Yuge et al. (2002) established the method to quantify the solar radiation reaching to the soil surface at a field using the fish-eye figure, considering the temporal and spatial changes of the solar radiation. Additionally, the procedure for the separating direct and diffuse solar radiations is introduced, considering the temporal and spatial changes of the solar radiation environment generated by the edge-effect.

\section{FIELD OBSERVATION}

To evaluate the edge-effect on the radiation environment of the farmland, the field observation was conducted at a tea field located in Jouyou town (E130 38', N33 ${ }^{\circ} 4^{\prime}$ ), Fukuoka Prefecture, in southwest Japan. Figure 1 shows the photographs of the study site. The area including the study site is classified as the hilly and mountainous areas, and the staple product in this area is tea. Most of the tea plantations are located on an inclined plane. As shown in Fig. 1, the south, east, and west parts of the study site are adjacent to the forest. The solar radiation is measured at two points shown in Fig. 1 using the pyranometers (LI-COR, LI-200). Additionally, to clarify the spatial distribution of the solar radiation, the field observation was conducted at an observational field set at Kyushu Univ. as shown in Fig. 2. The shelter, which is $1 \mathrm{~m}$ height and $2 \mathrm{~m}$ width, is set at the center of horizontal surface to describe the 


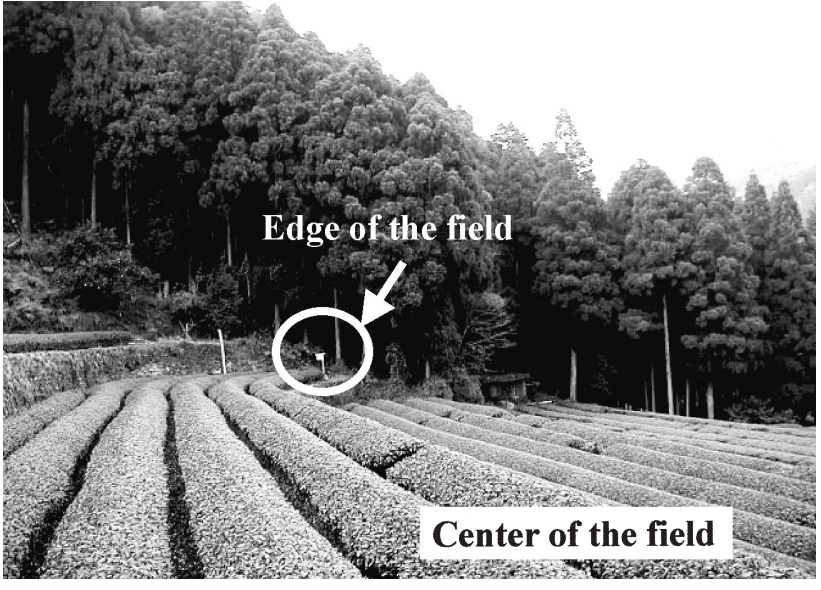

Fig. 1. Study site.

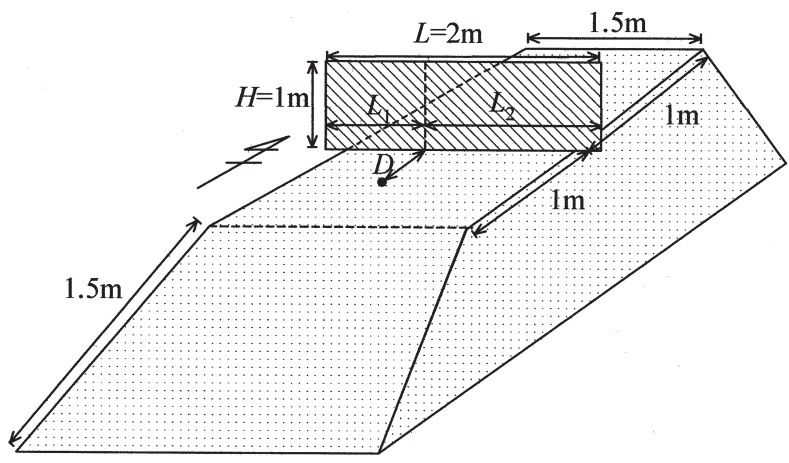

Fig. 2. Observational field.

forest at the actual field at the hilly and mountainous areas, and the horizontal surface is divided into two parts, facing the north and south.

\section{METHODLOGY}

The direct and diffused solar radiations are separately quantified to estimate the solar radiation reached the field surface, considering the edge-effect. The procedure for the separating direct and diffuse solar radiations suggested by IEA (International Energy Agency) is adopted in this study.

The total insolation $I_{H}$ for each time can be calculated as follows:

$$
I_{H}=\frac{\Pi Q}{2 T_{0}} \cos \frac{\Pi}{T_{0}}(T-12)
$$

where $Q$ is the daily total radiation, $T$ is the time, and $T_{0}$ is the maximum possible duration of sunshine or daylight hours.

The normal direct insolation $I_{N D}$ and horizontal direct insolation $I_{H D}$ can be estimated by following equations, respectively.

$$
\begin{aligned}
& I_{N D}=1791 \frac{I_{H}}{I_{0} \sin h}-547 \\
& I_{H D}=I_{N D} \sin h
\end{aligned}
$$

The diffuse insolation $I_{H S}$ can be calculated as follows:

$$
I_{H S}=I_{H}-I_{H D}
$$

The total solar radiation traveled to the field surface $R$ can be estimated as follows:

$$
R=I_{H D}+F_{s} I_{H S}=I_{H D}+\left(1-F^{\top}\right) I_{H S}
$$

where $F$ and $F_{s}$ are the view factors of the shelter and sky, respectively. When the field surface is covered with the shadow of the shelter, the only diffuse solar radiation can travel to the field surface.

The view factors of the shelter and sky can be estimated using the fish-eye projection (Yuge et al., 2001). However the view factor of the rectangular shelter as shown in Fig. 2 can be calculated by the following equations.

$$
\begin{aligned}
& f_{i}=\frac{1}{2 \pi}\left(\arctan \frac{1}{x_{i}}-\frac{1}{\sqrt{1+\left(\frac{y_{i}}{x_{i}}\right)^{2}}} \arctan \frac{1}{\sqrt{x_{i}^{2}+y_{i}^{2}}}\right)(6) \\
& x_{i}=\frac{D}{L_{i}} \quad y_{i}=\frac{H}{L_{i}} \\
& F=f_{1}+f_{2}
\end{aligned}
$$

\section{RESULTS AND DISCUSSION}

The daily total radiation data on 24th Oct. observed in Fukuoka weather station are used for analysis. The hourly total radiation is estimated using eq.(1), and the direct and diffuse insolations are separately estimated by eq. (3) and eq.(4). To estimate the view factor of the sky in the center and edge of the study site, the fish-eye projection method was introduced. Yuge et al. (2001) suggested the orthographic fish-eye method to estimate the solar radiation environment on the soil surface in crop field. In this study, the equal area fish-eye lens is introduced to estimate the view factor of the sky. The image processing is necessary when the equal area fish-eye projection is used for calculating the view factor. In this study, a software, Gap Light Analyzer (GLA), is introduced for the image processing and calculation of the view factor. Figure 3 shows the fish-eye projections taken at the center and edge of the field as shown in Fig. 1. The view factors of the sky at the center and edge of the field are 0.52 and 0.21 , respectively. The diffuse insolations at the center and edge of the study site are calculated by multiplying the diffuse insolation, estimated using eq. (2), by the view factors. The sun track on 24th Oct. is overlaid on the fish-eye 
projection as shown in Fig. 3. The sunlit and shaded periods at the center and edge can be clarified by these figures, and the direct solar radiation can reached the surface during the sunlit period.

Figure 4 shows the diurnal changes of the solar irradiance at the center and edge of the field. The simulation results show the good agreement with the observations. The daily total radiations at the center and edge of the field are shown in Fig. 5. The calculated results reproduce the observational data. The result indicates that the spatial difference of the dairy solar irradiance is very large as shown in Fig. 4, and it will affect the crop growth and agricultural productivity at the field.

Using the procedure for the separating direct and diffuse solar radiations, the spatial distribution of the

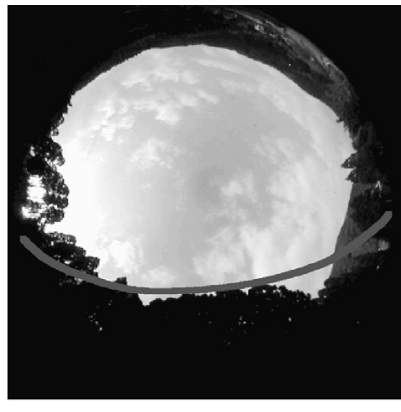

(a) Center of the field

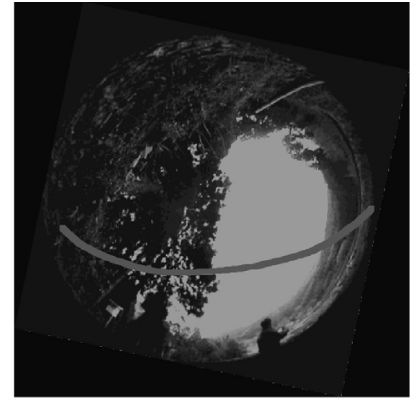

(b) Edge of the field
Fig. 3. Fish-eye projection at the center and edge of the field.

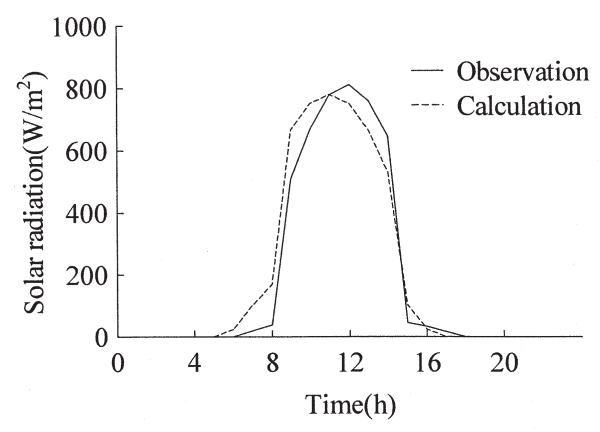

(a) Center of the field

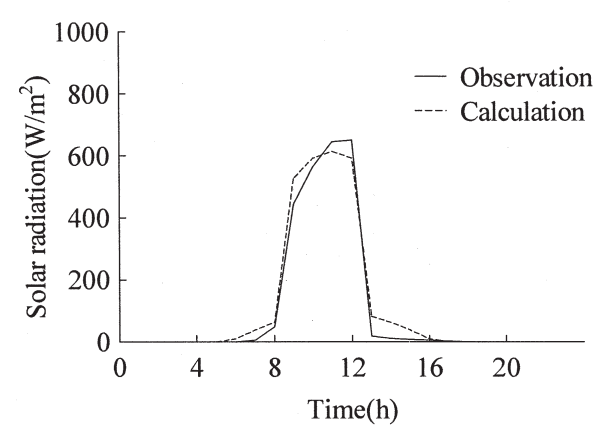

(b) Edge of the field

Fig. 4. Diurnal changes of the solar irradiance at the center and edge of the field. solar radiation environment is estimated at the observational field shown in Fig. 2. The total solar radiation was observed in the observational field every ten minute. The surface of the field is divided into $0.25 \mathrm{~m}$ times $0.1 \mathrm{~m}$ sections. The sunlit or shaded points on the field surface are clarified every time geometrically using the sun altitude, azimuth, and the shelter structure. The view factors of the shelter at the nodal points on the field surface are calculated using eq. (6) and (7). The diffuse insolations at the nodal points on the field surface are calculated using the view factors. Figure 6 shows the spatial distribution of the daily total radiation on the field surface. At the part facing the south, the solar radiation environment is almost spatially uniform. The result indicates that the solar irradiance at the field facing the north is very small at the vicinity of the shelter. The solar irradiance increases gradually with the distance from the shelter.

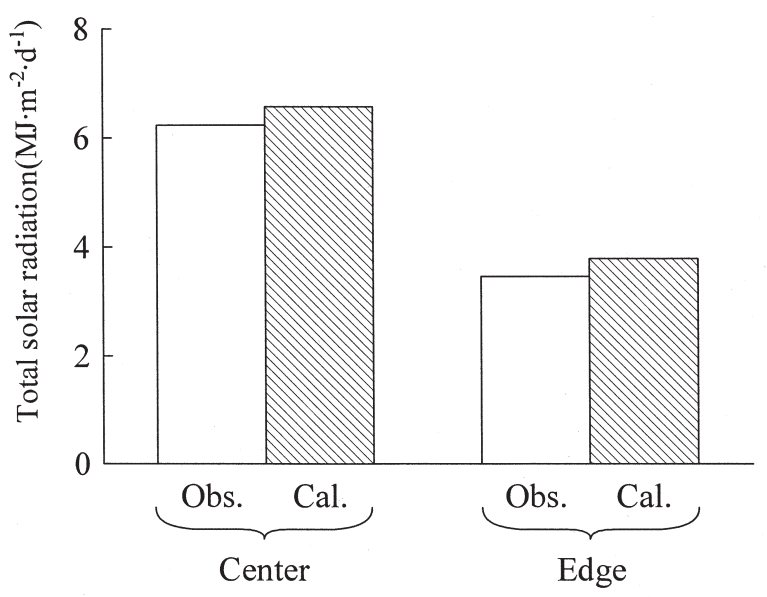

Fig. 5. Daily total radiations at the center and edge of the field.

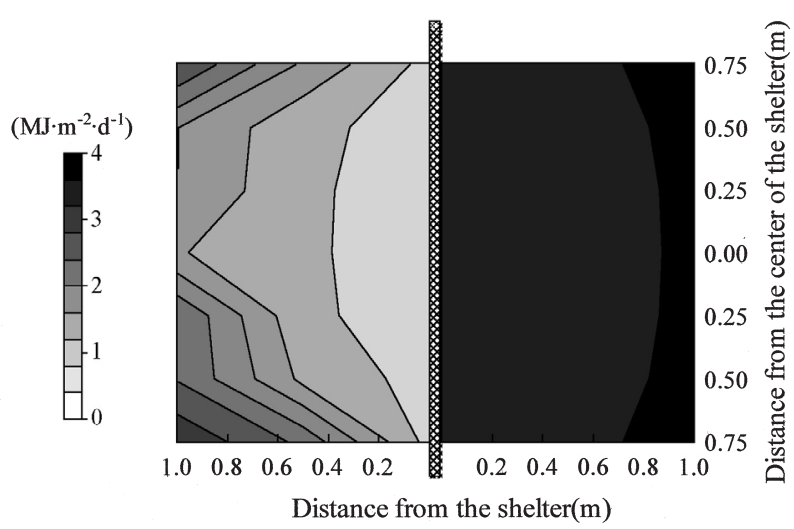

Fig. 6. Spatial distribution of the solar radiation environment at the observational field.

\section{CONCLUSIONS}

To evaluate the edge-effect on the solar radiation environment of the farmland located in the hilly and mountainous areas, the temporal and spatial changes of the solar radiation environment is clarified. Using the 
procedure for the separating direct and diffuse solar radiations and the fish-eye projection method, the diurnal changes of the solar radiation at the center and edge of the study site are estimated. The simulation result shows good agreement with the observation. Using this procedure, the spatial distribution of the solar radiation is estimated on the observational field, arranged to imitate the actual farmland adjacent to the shelter. The result indicates that the solar radiation environment on the field surface is affected by the shelter structure and the field directions. Using the method introduced here, the solar radiation environment in the hilly and mountainous areas can be clarified, considering the edge-effect. This will contribute to the farm planning and land use planning for the efficient agricultural production in the hilly and mountainous areas. The authors plan to compose the numerical model to simulate the thermal and soil water environment of the crop field under the edge-effect, using the solar irradiance estimated by this method as the input data for the model.

\section{REFERENCES}

Anderson, M. C. 1964 Studies of the woodland light climate, J. Ecol., 52: 26-41

Kurata K., M. Okada, and S. Sase 1988 Row orientation and direct solar radiation absorption of tomato canopy - Fisheye Photography Analysis -, J. Agri. Met., 44 (1): 15-22(in Japanese)

Miura T., T. Mitsuno, T. Maruyama and A. Yomota 1980 Calculation method of the distribution of the amount of insolation in mountainous areas-Studies on the mechanism of the thermal environment formation in mountainous area(1)-. Trans. JSIDRE, 88: 1-7(in Japanese)

Nakano Y., K. Yuge, T. Haraguchi, A. Marui, S. K. Saptomo and A. Hao 2005 Evaluation of the intrinsic environment changes resulted from the farmland consolidation in a hilled area. $J$. Agri. Meteorol., 60 (5): 713-716

Yuge, K., T. Haraguchi, Y. Nakano, M. Kuroda, and T. Funakoshi 2002 Estimating the solar radiation environment on the soil surface between rows using crop canopy architectural models. Trans. JSIDRE, 221: 25-32(in Japanese) 